\title{
Urologic Laparoscopic Surgeries in Elderly: Analysis of Pre-Operative Risk Factors and Postoperative Complications*
}

\author{
Sompol Permpongkosol \\ Division of Urology, Department of Surgery, Faculty of Medicine, Ramathibodi Hospital, Mahidol University, \\ Bangkok, Thailand \\ Email: sompolpermpong@gmail.com
}

Received June 15, 2013; revised July 18, 2013; accepted July 26, 2013

Copyright (C) 2013 Sompol Permpongkosol. This is an open access article distributed under the Creative Commons Attribution License, which permits unrestricted use, distribution, and reproduction in any medium, provided the original work is properly cited.

\begin{abstract}
Purpose: The aging of the population leads to increases in the prevalence of symptomatic urologic diseases. The aim of this study is the analysis of pre-operative risk factors and postoperative complications in patients over the age of 60 years undergoing elective laparoscopic urologic surgery. Patients and Methods: A retrospective study was conducted of 113 patients 60 years of age or older who underwent urologic laparoscopic surgery by a single surgeon (SP). The preoperative physical status and systemic complications, operation time, postoperative complications, postoperative hospital stay and other clinical features of the patients were reviewed. Complications were classified according to the recently revised Clavien classification system. Statistical analysis was done using Univariate analysis and the Fisher Exact test. Results: Laparoscopic urologic surgery was performed on 113 patients 60 years old and over, with an average age of 69.6 years. Associated diseases were found in $92 \%$ of them. Pelvic surgery $(65 ; 57.5 \%)$ was the main reason for surgery. There were $5(4.4 \%)$ conversions to open surgery and $0 \%$ mortality. The overall complication rate was 10 patients (8.8\%). Among 9 (7.96\%) patients with post-operative complications; Grade I, II, IIIa, IIIb and IV complications were observed in $1.77 \%, 12.8 \%, 3.53 \%, 0.88 \%$ and $0.88 \%$ of cases, respectively. Sex with male, operative time $\geq 250$ min and cancer had high risk ratio $(2.76,2.11$ and 3.02, respectively); however the correlations of all of preoperative risk factors and postoperative complications showed no statistically significant differences. Conclusions: Laparoscopic surgical treatment of urologic disease in elderly patients performed is feasible and well tolerated, with low perioperative morbidity and a good overall survival rate. Pre-operative risk factors may not influence postoperative complications in patients over the age of 60 years undergoing elective laparoscopic urologic surgery.
\end{abstract}

Keywords: Urologic; Laparoscopic Surgery; Elderly; Complications; Risk Factors; Clavien Classification System

\section{Introduction}

As the life-span of humans has increased, the prevalence of urologic disease has also increased with age. The estimated population of Thai elderly (60 and over) at the midyear of 2009 was 7,274,000 and life expectancy at sixty for males and females was 19.4 and 21.9 , respectively [1]. As a result, the number of elderly patients requiring urologic surgical procedures, particularly laparoscopic surgical procedures, is increasing [2]. During the last decade, laparoscopic procedures have increasingly become part of the standard surgical armamentarium in many urological centers and new applications for laparo-

${ }^{*}$ Conflict of interest: None declared. scopy continue to be reported [3]. Despite lack of elucidation of full-risk profiles, Efron et al. suggested that laparoscopic approaches should be considered regardless of a patient's age [4]. Therefore, it is important to analyze and continue updating laparoscopic surgical treatment in the elderly.

To our knowledge, there are many reports of laparoscopic nephrectomy in elderly patients [5-8]. Nevertheless, the current role of laparoscopic urologic surgery in older patients, especially in pelvic surgeries, has not been reported. To evaluate pre-operative risk factors and postoperative complications, we reported our experience of laparoscopic urologic surgery, early postoperative morbidity and analysis of pre-operative risk factors and postoperative complications in patients over the age of 60 
years undergoing elective laparoscopic urologic surgery.

\section{Patients and Methods}

We performed a retrospective review of a cohort of 113 consecutive patients who were aged at least 60 years at the time of undergoing laparoscopic urologic procedures, between July 2006 and December 2012 by a single surgeon (SP). This study was approved by Faculty of Medicine, Ramathibodi hospital, Mahidol University Review Board. Parameters examined included patient demographics, preoperative physical status and co-morbidities, complications, estimated blood loss (EBL), operative time, the American Society of Anesthesiologists score (ASA) class, and length of hospitalization were taken from hospital and outpatient records.

Complications were defined as in previous reports [9-12]: death was defined as any death that occurred within 30 days or any death at all related to the surgical procedure within 90 days. In addition, all complications were classified according to the Clavien classification system revised by Dindo et al. [13]. The original classification system consisted of four severity grades. The recently revised system emphasizes the risk and invasiveness of the therapy used to treat a complication and comprises mainly four important modifications: 1) lifethreatening complications were differentiated from complications treated in the ward; 2) CNS complications were included in the same category (Grade IV); 3) the length of hospital stay is no longer considered in the ranking; and 4) complications that can potentially lead to long-lasting disability are highlighted by a suffix " $d$ " (for "disability"). Consequently the new classification system comprises five severity grades.

Age, BMI and operative time are expressed as mean $( \pm \mathrm{SD})$. Hospital stay, creatinine and EBL are shown as median and range (min-max), because of non-normal distribution, and the categorical variables as percentage. Univariate analysis with Risk ratio (95\% confidence interval; CI) were performed to analyze the correlation of sex, age, body mass index, ASA score, hospital stay, creatinine, type of surgery, operative time, blood transfusion, estimated blood loss and cancer with complications. Fisher's exact test was performed to analyze the correlation of age and operative time, estimated blood loss or hospital stay. A p-value $<0.05$ was considered statistically significant.

\section{Results}

The characteristics of patients were listed in Table $\mathbf{1}$. The majority of laparoscopic urologic surgeries on the elderly in this series are on men $(84 ; 74.3 \%)$. The mean patient age was 69.6 yrs (60 - 91 yrs) and the mean body mass index (BMI) was $24.4 \mathrm{~kg} / \mathrm{m}$ [2] (17.6 - 32.8). Asso- ciated diseases were found in $92 \%$ of the patients; the main diseases being hypertension $(76 ; 67.25 \%)$ dyslipidemia $(33 ; 29.2 \%)$ and diabetes mellitus type II (29; $25.67 \%)$.

All cases were done by transperitoneal incision and admitted electively. (Table 2) Non-pelvic surgery (39; $43.5 \%)$, pelvic surgery $(65 ; 57.5 \%)$ and both non-pelvic and pelvic simultaneously $(9 ; 7.96 \%)$ were undertaken. For non pelvic surgery (39), we performed 17 nephroureterectomies $(43.6 \%), 8$ nephrectomies $(20.5 \%)$ and 7 renal cyst ablations (17.95\%). Laparoscopic radical prostatectomy $(48 ; 73.85 \%)$ and laparoscopic radical cystectomy with ileal conduit $(9 ; 13.85 \%)$ respectively were the main pelvic surgeries (65).

The mean operative time was $250.8 \mathrm{~min}(100-540$ min) and the mean blood loss was $568.7 \mathrm{ml}$ (50 - 3500 $\mathrm{ml})$. Blood transfusion treatment was given to 37 patients $(32.7 \%)$. The main reasons for conversion to open surgery $(5 ; 44 \%)$ were technical difficulty and lack of progress with the operation. The overall complication rate was $8.8 \%(10 / 113) ; 1(0.88 \%)$ patient with intraoperative complications included rectal injury. Among 9 (7.96\%) patients with post-operative complications; Grade I, II, IIIa, IIIb and IV complications were observed in $1.77 \%$, $12.8 \%, 3.53 \%, 0.88 \%$ and $0.88 \%$ of cases, respectively. Lumbosacral plexopathy [1] and anastomotic urine leakage were included in Grade I. Grade II included cases of deep vein thrombosis [1]. Urinoma [2], anastomotic strictures [1] and postoperative wound infections requiring secondary suture [1] were included in the Grade IIIa category. Grade IIIb included incisional hernia [1]. Sepsis requiring ICU management in one patient was of Grade IV.

Complications were shown sex with male (RR 2.76, $95 \%$ CI 0.36 to 21.14 , p-value 0.328 ), operative time $\geq$ $250 \mathrm{~min}$ (RR 2.1, 95\% CI 0.6 to 7.44, p-value 0.201), and cancer (RR 3.02, 95\% CI 0.39 to 23.19, p-value 0.234 ) had high risk ratio. However, the correlations of none of the preoperative risk factors or postoperative complications were statistically significant different (Table 3 ). When stratified by age $<70$ and $\geq 70$ years old, no statistically significant difference was found in operative time, estimated blood loss or hospital stay (Table 4). The mortality rate in our series was $0 \%$. The mean hospital stay was $6(1-60)$ days.

\section{Discussion}

Laparoscopic surgery has proved to be a secure and feasible technique in the treatment of benign renal pathology in pediatric patients with satisfactory results [14-16]. Actually the indications are expanding to reconstructive procedures, with promising results, and selected oncologic procedures. In contrast, several aspects of laparo- 
Table 1. Patient characteristics.

\begin{tabular}{|c|c|c|}
\hline Characteristics & Number & $\%$ \\
\hline \multicolumn{3}{|l|}{ Sex } \\
\hline Male & 84 & 74.3 \\
\hline Female & 29 & 25.7 \\
\hline Age, year, mean $( \pm \mathrm{SD})$ & 113 & $69.6(6.9)$ \\
\hline BMI, mean ( \pm SD) & 113 & $24.4(3.1)$ \\
\hline \multicolumn{3}{|l|}{ ASA score } \\
\hline Level 2 & 37 & 32.7 \\
\hline Level 3 & 67 & 59.3 \\
\hline Level 4 & 9 & 8.0 \\
\hline Hospital stay, median (range) & 113 & $6(1.60)$ \\
\hline $\mathrm{Hb}$, mean $( \pm \mathrm{SD})$ & 113 & $12.7(1.9)$ \\
\hline $\mathrm{Cr}$, median (range) & 112 & $1.0(0.1,5.3)$ \\
\hline \multicolumn{3}{|l|}{ Pelvic surgery } \\
\hline Pelvic \& mix & 9 & 7.96 \\
\hline Pelvic alone & 65 & 57.5 \\
\hline Non-pelvic & 39 & 34.5 \\
\hline Operative time, mean $( \pm \mathrm{SD})$ & 113 & $250.8(97.9)$ \\
\hline \multicolumn{3}{|l|}{ Blood transfusion } \\
\hline Yes & 37 & 32.7 \\
\hline No & 76 & 67.3 \\
\hline Estimated blood loss, median (range) & 113 & $568.7(0.3500)$ \\
\hline \multicolumn{3}{|l|}{ Cancer } \\
\hline Yes & 82 & 72.6 \\
\hline No & 31 & 27.4 \\
\hline \multicolumn{3}{|l|}{ Complication } \\
\hline Yes & 9 & 7.9 \\
\hline No & 104 & 92.1 \\
\hline
\end{tabular}

Table 2. Postoperative complication for each procedure of laparoscopic urologic surgery.

\begin{tabular}{|c|c|c|c|}
\hline Procedures & No. $(\%)$ & Open conversion & Postoperative complication \\
\hline Laparoscopic non-pelvic surgery & $39(34.5 \%)$ & $2(1.76 \%)$ & $3(2.65 \%)$ \\
\hline 1) adrenalectomy & 1 & - & - \\
\hline 2) nephrectomy & $8^{*}$ & - & - \\
\hline 3) renal tumor ablation & 3 & - & Urinoma (Grade II) \\
\hline 4) renal cystic decortication & $7^{*}$ & - & - \\
\hline 5) pyeloplasty & 0 & - & - \\
\hline 6) ureterolithotomy & 2 & - & - \\
\hline 7) nephroureterectomy & 17 & 2 & Incisional hernia (Grade IIIb) \\
\hline 8) partial $\mathrm{Nx}$ & 1 & - & Urinoma (Grade II) \\
\hline Langrosconic nolvic surory & & & $6(5.3 \%)$ \\
\hline $\begin{array}{l}\text { Laparoscopic pelvic surgery } \\
\text { 1) radical prostatectomy }\end{array}$ & $\begin{array}{c}65(57.5 \%) \\
48\end{array}$ & $3(2.65 \%)$ & Anastomotic urine leakage (Grade I), deep vein thrombosis (Grade II), \\
\hline 2) urachal cyst removal & $\begin{array}{c}48 \\
2\end{array}$ & 2 & Anastomotic strictures (Grade II), postoperative wound infections \\
\hline 3) reimplantation ureter & $\begin{array}{l}2 \\
1\end{array}$ & - & Requiring secondary suture (Grade IIIa) \\
\hline 4) assisted simple cystectomy & 1 & - & - \\
\hline 5) partial cystectomy & 2 & - & - \\
\hline 6) radical cystectomy with ileal & 9 & - & 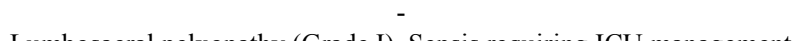 \\
\hline conduit & & & Lumbosacral pelxopathy (Grade I), Sepsis requiring ICU management \\
\hline 7) ileal conduit & 1 & 1 & (Grade IV) \\
\hline 8) iliac LN dissection & 1 & - & - \\
\hline 9) uretectomy & 1 & - & $\begin{array}{l}- \\
-\end{array}$ \\
\hline $\begin{array}{l}\text { Laparoscopic pelvic-non pelvic } \\
\text { surgery (simultaneous) }\end{array}$ & $9(7.96 \%)$ & $\mathbf{0}$ & 0 \\
\hline $\begin{array}{l}\text { 1) laparoscopic nephroureterectomy } \\
\text { with bladder cuff }\end{array}$ & 9 & 0 & 0 \\
\hline Total & 113 & $5(4.4 \%)$ & $9(7.96 \%)$ \\
\hline
\end{tabular}

*Laparoendoscopic single site surgery. 
Table 3. Univariate analysis of preoperative risk factors and postoperative complications in the patients over the age of 60 years undergoing elective laparoscopic urologic surgery.

\begin{tabular}{|c|c|c|c|c|c|c|}
\hline \multirow{2}{*}{ Factor } & \multirow{2}{*}{$\mathbf{N}$} & \multicolumn{2}{|c|}{ Complication } & \multirow{2}{*}{ Risk ratio } & \multirow{2}{*}{$95 \%$ CI } & \multirow{2}{*}{ p-value } \\
\hline & & Yes & No & & & \\
\hline \multicolumn{7}{|l|}{ Sex } \\
\hline Male & 84 & $8(9.5)$ & $76(90.5)$ & 2.76 & $0.36,21.14$ & 0.328 \\
\hline Female & 29 & $1(3.4)$ & $28(95.6)$ & 1 & & \\
\hline \multicolumn{7}{|l|}{ Age } \\
\hline$\geq 70$ & 56 & $5(8.9)$ & $51(91.1)$ & 1.27 & $0.36,4.50$ & 0.489 \\
\hline$<70$ & 57 & $4(7.0)$ & $53(93.0)$ & 1 & & \\
\hline \multicolumn{7}{|l|}{ BMI } \\
\hline$\geq 25$ & 47 & $4(8.5)$ & $43(91.5)$ & 1.12 & $0.32,3.96$ & 0.561 \\
\hline$<25$ & 66 & $5(7.6)$ & $61(92.4)$ & 1 & & \\
\hline \multicolumn{7}{|l|}{ ASA score } \\
\hline Level 2 & 37 & $4(10.8)$ & $33(89.2)$ & 0.61 & $0.17,2.13$ & 0.331 \\
\hline Level 3 and Level 4 & 76 & $5(6.6)$ & $71(93.4)$ & 1 & & \\
\hline Hospital stay, mean (SD) & 113 & $14.3(6.1)$ & $6.5(0.4)$ & 1.05 & $1.04,1.07$ & 0.258 \\
\hline \multicolumn{7}{|l|}{$\mathrm{Hb}$} \\
\hline$<11$ & 17 & $0(0)$ & $17(100.0)$ & 0.28 & $0.02,4.66$ & 0.217 \\
\hline$\geq 11$ & 96 & $9(9.4)$ & 87 (90.6) & 1 & & \\
\hline $\mathrm{Cr}$, mean $(\mathrm{SD})$ & 113 & $1.1(0.1)$ & $1.2(0.1)$ & 0.52 & $0.10,2.74$ & 0.441 \\
\hline \multicolumn{7}{|l|}{ Pelvic Sx } \\
\hline Pelvic \& mix & 9 & $0(0)$ & $9(100.0)$ & $0.03^{*}$ & $-1.42,1.48$ & 0.967 \\
\hline Pelvic alone & 65 & $6(9.3)$ & $59(90.7)$ & & & \\
\hline Non-pelvic & 39 & $3(8.6)$ & $36(91.4)$ & 1 & & \\
\hline \multicolumn{7}{|l|}{ Operative time } \\
\hline$\geq 250 \mathrm{~min}$ & 42 & $5(11.9)$ & $37(88.1)$ & 2.11 & $0.60,7.44$ & 0.201 \\
\hline$<250 \min$ & 71 & $4(5.6)$ & $67(94.4)$ & 1 & & \\
\hline \multicolumn{7}{|l|}{ Blood transfusion } \\
\hline Yes & 37 & $3(8.1)$ & 34 (91.9) & 1.03 & $0.27,3.88$ & 0.615 \\
\hline No & 76 & $6(7.9)$ & $70(62.1)$ & 1 & & \\
\hline \multicolumn{7}{|l|}{ Estimated blood loss } \\
\hline$\geq 570 \mathrm{ml}$ & 35 & $3(8.6)$ & $32(91.4)$ & 1.11 & $0.30,4.20$ & 0.569 \\
\hline$<570 \mathrm{ml}$ & 78 & $6(7.7)$ & $72(92.3)$ & 1 & & \\
\hline \multicolumn{7}{|l|}{ Cancer } \\
\hline Yes & 82 & $8(9.8)$ & $74(90.2)$ & 3.02 & $0.39,23.19$ & 0.234 \\
\hline No & 31 & $1(3.2)$ & $30(96.8)$ & 1 & & \\
\hline
\end{tabular}

*Risk ratio is combine pelvic \& mix and pelvic alone.

Table 4. Subgroup analysis, age of patients (Fisher's exact test).

\begin{tabular}{|c|c|c|c|c|}
\hline \multirow{2}{*}{ Factor } & \multirow{2}{*}{$\mathbf{N}$} & \multicolumn{2}{|c|}{ Age (yr) } & \multirow{2}{*}{ p-value } \\
\hline & & $<70$ & $\geq 70$ & \\
\hline \multicolumn{5}{|l|}{ Operative time } \\
\hline$<250 \min$ & 71 & $34(47.9)$ & $37(52.1)$ & 0.305 \\
\hline$\geq 250 \mathrm{~min}$ & 42 & $23(54.8)$ & $19(45.2)$ & \\
\hline \multicolumn{5}{|l|}{ Estimated blood loss } \\
\hline$<570 \mathrm{ml}$ & 78 & $36(46.2)$ & $42(53.8)$ & 0.123 \\
\hline$\geq 570 \mathrm{ml}$ & 35 & $21(60.0)$ & $14(40.0)$ & \\
\hline Hospital stay (days), median (range) & 113 & $5(2.24)$ & $6(1.60)$ & 0.298 \\
\hline
\end{tabular}


scopy impose unique physiologic stresses and, as such, may alter surgical risk to the geriatric patient [17-19]. The incidence of hypertension, atherosclerosis, and chronic pulmonary complications are all elevated in patients aged 65 and older [20,21]. Hypertension is among the diseases that are most significantly increased in our report. Therefore, patients should be carefully selected for one of the surgical treatments according to their health, fitness, wishes and the experience of the referred centre. Advanced age is not an absolute contraindication for many laparoscopic procedures. To our knowledge, a lot of cohort studies $[2,8]$ report only non pelvic urologic surgeries in elderly patients. Varkarakis et al. [8] and Lai et al. [7] described outcomes in patients aged 75 years or older undergoing laparoscopic nephrectomy which showed no differences in the complication rates, blood loss and operative times [9].

Evaluation of the pre-operative risk factors and postoperative complications are important factors in selecting surgical treatment for elderly patients. Despite the higher percentage of underlying disease in our series, urologic laparoscopy with elderly patients presenting with urinary problems is a safe modality in a university hospital, with no evidence of increased morbidity and mortality. In the current report most of the postoperative complications were Grade II (12.8\%) as minor complications. There was only one Grade IV $(0.88 \%)$ case; which is similar to many reports [22-24].

According to Zhao et al.'s reports [2], overall, there was no statistically significant increase in perioperative complications related to age and patients 75 and older, but they had a significantly longer stay than patients between 65 and 74 years. Our report demonstrated that sex with male, operative time $\geq 250 \mathrm{~min}$ and cancer had high risk ratio $(2.76,2.11$ and 3.02 , respectively). Nevertheless, there was no correlation of sex, age, body mass index, ASA score, hospital stay, creatinine, type of surgery, operative time, blood transfusion, estimated blood loss and cancer with complications in these studies.

Procedures involving pelvic anatomy (urachus, bladder and prostate bladder) necessitate that the patient is in the Trendelenburg position which will affect cerebrovascular, respiratory and hemodynamic homeostasis [4, 25]. The complications of laparoscopic pelvic surgery $(65 ; 57.5 \%)$ seem to be more than those of laparoscopic non-pelvic surgery in the current report.

A major reason for converting to an open procedure, or choosing to perform an open procedure in the first place, is presence of inflammation [4] due to complicated disease. This reason should well explain why the operation was technically difficulty and did not progress in our conversion cases. Conversion should never be regarded as a failure, but as a decision to perform the safest, mostappropriate procedure for a patient, especially for older patients at the highest risk of complications.

Our report demonstrated that age has minimal impact on the outcome for elderly patients who undergo laparoscopic surgery for urologic disease. When stratified by age $<70$ and $\geq 70$ years old, no statistically significant difference was found in operative time, estimated blood loss or hospital stay. There are limitations with regard to the small sample, but this study is the first report of laparoscopic urologic surgery in elderly patients that specifies the type of surgeries as pelvic and non-pelvic surgeries.

\section{Conclusion}

Laparoscopic surgery is a safe and accepted procedure in patients over 60 years of age with urologic disease. There was no significant increase in perioperative complications related to age, and pre-operative risk factors may not influence postoperative complications in patients over the age of 60 years undergoing elective laparoscopic urologic surgery.

\section{Acknowledgements}

The author thanks Terry King for his assistance preparing the article and Assoc. Prof. Sasitorn Yongcharoen for the statistical analysis.

\section{REFERENCES}

[1] Institute for Population and Social Research MU, "All about Population," 2009. www.ipsr.mahidol.ac.th

[2] L. C. Zhao, R. A. Rubenstein, I. Y. Vardi, C. Tenggardjaja, N. Smith and R. B. Nadler, "Effect of Advanced Age on Laparoscopic Urologic Procedures," Journal of Endourology, Vol. 21, No. 1, 2007, pp. 62-64. doi:10.1089/end.2006.9997

[3] R. Ganzer, R. Rabenalt, M. C. Truss, S. Papadoukakis, M. Do, A. Blana, et al., "Evaluation of Complications in Endoscopic Extraperitoneal Radical Prostatectomy in a Modular Training Programme: A Multicentre Experience," World Journal of Urology, Vol. 26, No. 6, 2008, pp. 587593. doi:10.1007/s00345-008-0291-y

[4] D. T. Efron and J. S. Bender, "Laparoscopic Surgery in Older Adults," Journal of the American Geriatrics Society, Vol. 49, No. 5, 2001, pp. 658-663. doi:10.1046/j.1532-5415.2001.49130.x

[5] M. Harano, M. Eto, A. Yokomizo, K. Tatsugami, M. Hamaguchi and S. Naito, "The Efficacy of Laparoscopic Radical Nephrectomy for Renal Cell Cancer in the Elderly: An Oncological Outcome Analysis," International Journal of Urology, Vol. 15, No. 7, 2008, pp. 577-581. doi:10.1111/j.1442-2042.2008.02054.x

[6] T. H. Hsu, L. M. Su, L. E. Ratner and L. R. Kavoussi, "Laparoscopic Donor Nephrectomy in the Elderly Patient," Urology, Vol. 60, No. 3, 2002, pp. 398-401. doi:10.1016/S0090-4295(02)01769-7 
[7] F. C. Lai, E. L. Kau C. S. Ng and G. J. Fuchs, "Laparoscopic Nephrectomy Outcomes of Elderly Patients in the 21st Century," Journal of Endourology, Vol. 21, No. 11, 2007, pp. 1309-1313. doi:10.1089/end.2007.9885

[8] I. Varkarakis, R. Neururer, T. Harabayashi, G. Bartsch and R. Peschel, "Laparoscopic Radical Nephrectomy in the Elderly," BJU International, Vol. 94, No. 4, 2004, pp. 517-520. doi:10.1111/j.1464-410X.2004.04994.x

[9] S. Permpongkosol, P. Ungbhakorn and C. Leenanupunth, "Laparo-Endoscopic Single Site (LESS) Management of Benign Kidney Diseases: Evaluation of Complications," Journal of the Medical Association of Thailand, Vol. 94, No. 1, 2011, pp. 43-49.

[10] S. Permpongkosol, G. C. Lima, C. A. Warlick, M. E. Allaf, I. M. Varkarakis, H. S. Bagga, et al., "Postchemotherapy Laparoscopic Retroperitoneal Lymph Node Dissection: Evaluation of Complications," Urology, Vol. 69, No. 2, 2007, pp. 361-365. doi:10.1016/j.urology.2006.10.020

[11] S. Permpongkosol, R. E. Link, L. M. Su, F. R. Romero, H. S. Bagga, C. P. Pavlovich, et al., "Complications of 2775 Urological Laparoscopic Procedures: 1993 to 2005," Journal of Urology, Vol. 177, No. 2, 2007, pp. 580-585. doi:10.1016/j.juro.2006.09.031

[12] G. H. Ballantyne, J. Svahn, R. F. Capella, J. F. Capella, H. J. Schmidt, A. Wasielewski, et al., "Predictors of Prolonged Hospital Stay Following Open and Laparoscopic Gastric Bypass for Morbid Obesity: Body Mass Index, Length of Surgery, Sleep Apnea, Asthma, and the Metabolic Syndrome," Obesity Surgery, Vol. 14, No. 8, 2004, pp. 1042-1050. doi:10.1381/0960892041975460

[13] D. Dindo, N. Demartines and P. A. Clavien, "Classification of Surgical Complications: A New Proposal with Evaluation in a Cohort of 6336 Patients and Results of a Survey," Annals of Surgery, Vol. 240, No. 2, 2004, pp. 205-213. doi:10.1097/01.sla.0000133083.54934.ae

[14] J. Dingemann and B. M. Ure, "Systematic Review of Level 1 Evidence for Laparoscopic Pediatric Surgery: Do Our Procedures Comply with the Requirements of Evidence-Based Medicine?" European Journal of Pediatric Surgery, 2013 Feb 26.

[15] R. Vecchio, S. Marchese and E. Intagliata, "Pediatric Laparoscopic Splenectomy in a Department of General Surgery," Updates in Surgery, 2012 Nov 30.

[16] F. T. Denes, A. Tavares, E. D. Monteiro, J. de Bessa Jr.,
A. M. Giron, F. A. Queiroz Filho, et al., "Laparoscopic renal Surgery in Infants and Children: Is It a Feasible and Safe Procedure for All Pediatric Age Groups?" International Brazilian Journal of Urology, Vol. 34, No. 6, 2008, pp. 739-746. doi:10.1590/S1677-55382008000600009

[17] J. Majeski, "Laparoscopic Cholecystectomy in Geriatric Patients," The American Journal of Surgery, Vol. 187, No. 6, 2004, pp. 747-750. doi:10.1016/j.amjsurg.2003.11.031

[18] P. Fornara, C. Doehn and D. Jocham, "Laparoscopic Nephrectomy in Geriatric Patients: Comparison with Conventional Nephrectomy," Zeitschrift für Gerontologie und Geriatrie, Vol. 33, No. 5, 2000, pp. 388-395. doi: $10.1007 / \mathrm{s} 003910070036$

[19] J. M. Velasco, V. L. Vallina, D. J. Esposito and S. Theodore, "Laparoscopic Herniorrhaphy in the Geriatric Population," The American Journal of Surgery, Vol. 64, No. 7, 1998, pp. 633-637.

[20] J. A. Lujan, F. Sanchez-Bueno, P. Parrilla, R. Robles, J. A. Torralba and R. Gonzalez-Costea, "Laparoscopic vs Open Cholecystectomy in Patients Aged 65 and Older," Surgical Laparoscopy \& Endoscopy, Vol. 8, No. 3, 1998, pp. 208-210. doi:10.1097/00019509-199806000-00009

[21] I. Gunka, J. Dostalik, L. Martinek, P. Gunkova, M. Mazur and P. Vavra, "Advanced Age-Indication or Contraindication for Laparoscopic Colorectal Surgery?” Rozhledy $v$ Chirurgii, Vol. 89, No. 10, 2010, pp. 628-633.

[22] M. Burchardt and J. U. Stolzenburg, "Complications in Laparoscopic Urology," World Journal of Urology, Vol. 26, No. 6, 2008, pp. 521-522. doi:10.1007/s00345-008-0353-1

[23] C. C. Passerotti, H. T. Nguyen, A. B. Retik and C. A. Peters, "Patterns and Predictors of Laparoscopic Complications in Pediatric Urology: The Role of Ongoing Surgical Volume and Access Techniques," Journal of Urology, Vol. 180, No. 2, 2008, pp. 681-685. doi:10.1016/j.juro.2008.04.042

[24] G. Vallancien, X. Cathelineau, H. Baumert, J. D. Doublet and B. Guillonneau, "Complications of Transperitoneal Laparoscopic Surgery in Urology: Review of 1311 Procedures at a Single Center," Journal of Urology, Vol. 168, No. 1, 2002, pp. 23-26. doi:10.1016/S0022-5347(05)64823-9

[25] D. M. Gainsburg, "Anesthetic Concerns for Robotic-Assisted Laparoscopic Radical Prostatectomy," Minerva Anestesiologica, Vol. 78, No. 5, 2012, pp. 596-604. 